\section{The anaesthetic machine}

Safe use of the anaesthetic gas machine, in common with all mechanical devices, can be viewed as an interaction between the basic design and safety features of the machine itself, the knowledge and skills of the operator, and the specific procedures employed by the operator using the device. This discussion will emphasize the design and safety features of the anaesthetic machine itself, and must of necessity exclude the important factors relating to the operator. Operating procedures will be discussed only in the context of establishing a pre-use checklist for the anaesthetic machine.

For convenience, and in particular because current standards for anaesthetic gas machines are so structured, the anaesthetic machine will be considered as a unit which begins at the point of attachment of the machine to the source of gases and ends at the common gas outlet. Components within these two points, such as vapourizers, will be included while external components, such as anaesthetic breathing circuits, will not be considercd.

The road to current Canadian design and safety requirements for anaesthetic gas machines has been long and deliberate. The publication of the Canadian Standards Association's (CSA) preliminary standard for anaesthetic gas machines in $1978^{1}$ followed many years of deliberation by a CSA committee composed of representatives from manufacturers, users and regulatory authorities with guidance from CSA staff. The preliminary standard was replaced by a definite one published in $1980,{ }^{2}$ differing mainly by the addition of test procedures to the basic requirements established in the 1978 version and by the addition of a preface concerning implementation of the standard. This preface comments that although the requirements of the standard were not intended to be applied retroactively, the CSA Technical Committee on Anaesthetic Equipment and Respiratory Technology urged that all anaesthetic machines should comply with certain basic requirements, as summarized in Table $\mathrm{I}$.

An American National Standards Institute equivalent standard was published in 1979.3 More
TABLE I Design requirements of 1978 and 1980 CSA anaesthetic machine standards

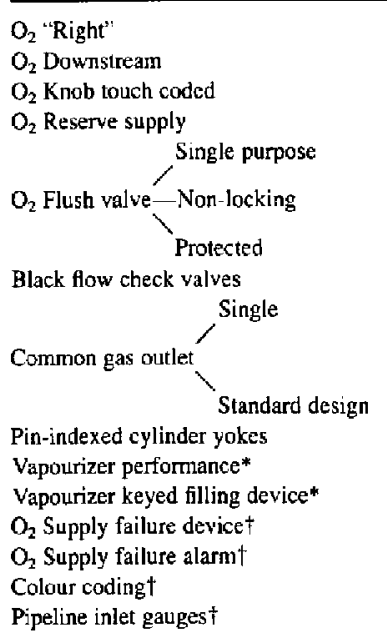

*Included in 1980 Standard Preface, excluded from Manitoba programme. See Text.

TIncluded in Manitoba Programme, excluded from 1980 Standard Preface. See Text.

recently the Health Protection Branch of Health and Welfare Canada has declared its intention to establish, under the Foods and Drugs Act, mandatory standards for anaesthetic machines. ${ }^{4}$

The province of Manitoba, in a programme completed in 1980, upgraded or replaced every anaesthctic machine, used for patient care, in the province. $^{5}$ To date no other province has achieved similar uniform adherence to the basic requirements of the CSA standard.

The Manitoba programme involved the co-operation of the Manitoba Health Service Commission as the sponsoring agency, the Manitoba Health Organizations as the implementing and co-ordinating agency and two members of the Department of Anaesthesia, Health Sciences Centre and University of Manitoba as advisors. Under the programme 65 anaesthetic machines were purchased on a group tender basis for a total cost of $\$ 175,000$ while 127 machines were upgraded at a cost of $\$ 100,000$. As summarized in Table $I$, the programme went beyond the recommendations of the preface to the 1980 Standard. Three machines were found to be already satisfactory while 17 of a total of 212 
TABLE II Components of pre-use anaesthetic machine checklist

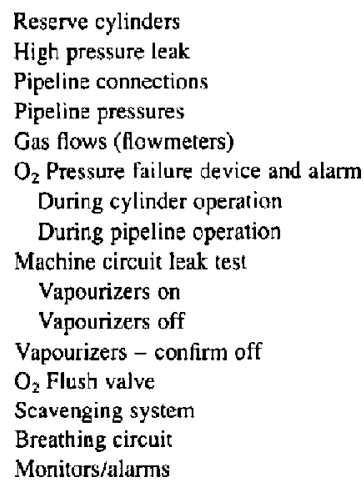

machines were found not to be required and were permanently removed from service.

The exclusion of vapourizers from the 1980 Manitoba programme was deliberate, resulting from a decision by the advisors that attention to the basic anaesthetic machine was most urgent at the time, and that a future separate programme could accommodate requirements of a standard for vapourizers. Inclusion of items which were part of the CSA standard, but excluded from the 1980 standard preface (Table I) was the result of a decision to meet all the basic requirements of the standards in one programme at one time. Neither decision has led to any significant problems.

The route in Canada to basic design and safety features for anaesthetic gas machines is therefore clear. Purchase orders for anaesthetic machines should specify that the machine has been certified by the CSA as conforming to the 1980 standard, its amendments or future editions. Until the current proposed Health Protection Branch standards for anaesthetic machines are enacted and enforced under the Food and Drugs Act as mandatory standards, adherence to the existing CSA standards will remain voluntary. The co-operation of all anaestherists is required through their insistence that all equipment purchased must conform with the appropriate CSA standards.

Because the life of anaesthetic gas machines is so long, often in excess of 20 years, it would be preferable if existing machines which do not warrant replacement at this time could be upgraded, as in the Manitoba programme summarized above. The Manitoba goal of uniform design and safety requirements for every anaesthetic machine used for patient care is an appropriate objective for all of Canada.

As outlined initially, the safe use of anaesthetic machines requires much more than inherently safe devices. Each anaesthetist should develop a pre-use andesthetic machine check which is approptiate for the anaesthetic machine and breathing circuit in use. Suggested components of such a check procedure are listed in Table II

\section{References}

1 Continuous flow inhalation anesthetic apparatus (anesthetic machines) for medical use. CSA Preliminary Standard Z168.3-M 1978. Canadian Standards Association, Rexdale (1978).

2 Continuous flow inhalation anaesthetic apparatus (anaethetic machines) for medical use. CSA Standard Z168.3-M1980. Canadian Standards Association, Rexdale (1980)

3 Minimum performance and safety requirements for components and systems of continuous-flow anesthesia machines for human use. ANSI Standard Z79.8-1979. American National Standards Institute, New York.

4 Proposed standards for anaesthesia machines, anaesthesia vapourizers, and keyed filling devices. Information Letter no. 633, August 27, 1983, Health Protection Branch, Health and Welfare Canada, Ottawa.

5 Craig DB, Longmuir J. Implementation of Canadian Standards Association Z168.3-M 1980. Anaesthetic gas machine standard: The Manitoba experience. Can Anaesth Soc J 1980;27:504-9.

\section{Safe use of the anaesthetic ventilator}

In terms of ventilator design, the anaesthetic ventilator is a relatively simple and reliable machine. Nevertheless it can and does occasionally fail to perform properly, often in subtle ways that are not clearly obvious to the user. 